\title{
CARACTERIZAÇÃO GEOAMBIENTAL DA SUB-BACIA DO RIO SALGADO NA MESORREGIÃO SUL CEARENSE - Parte I - Clima e Arcabouço Geológico
}

\author{
Simone Cardoso Ribeiro \\ Professora Associada - Dept. Geociências - Universidade Regional do Cariri (URC)
}

\section{Resumo}

A sub-bacia hidrográfica do rio Salgado, afluente da Bacia do rio Jaguaribe, está situada na porção sudeste do Estado do Ceará, e drena todo o Vale do Cariri, região diferenciada em meio ao semiárido nordestino devido à perenidade da maioria de seus cursos d'água, constituindo as veias do Cariri cearense. Pretendese apresentar os elementos constituintes da paisagem desta sub-bacia de acordo com a conceituação geossistêmica de Bertrand (1971), uma vez que este agrega estudos sobre fenômenos espaciais, geográficos, em que os elementos físico-biológicos e sócio-econômico-culturais se relacionam e produzem um espaço diferenciado. Assim, neste primeiro artigo sobre a Geografia Física Global da sub-bacia do rio Salgado, objetiva-se apresentar alguns elementos constituintes de sua paisagem de forma pormenorizada - os aspectos climáticos e a base geológico-estrutural da área. Para tanto foram utilizados trabalhos de levantamentos destes recursos naturais por órgão oficiais do Estado brasileiro (Ministério de Minas e Energia - MME/Projeto RADAMBRASIL, Superintendência para o Desenvolvimento do Nordeste - SUDENE, Instituto Brasileiro de Geografia e Estatística - IBGE, Fundação Cearense de Meteorologia e Recursos Hídricos - FUNCEME, Companhia de Gestão dos Recursos Hídricos - COGERH), assim como de teses e publicações acadêmicas sobre a área de estudo.

Palavras-Chaves: Geossistema. Cariri Cearense. Paisagem.

\section{Abstract}

The sub-basin of the Salgado river, a tributary of the Jaguaribe river, is located in the southeastern portion of the State of Ceará, and drains all the Valley of Cariri, differentiated region amid the northeastern semi-arid region due to the continuation of most of its watercourses 'water, making the veins of Cariri cearense. It is intended to present the landscape of the constituent elements of this sub-basin according to geosystemic concept of Bertrand (1971), since this adds studies of spatial phenomena, geographical, in which the physical and biological elements and socio-economic-cultural they relate and produce a different space. Thus, this first article on Geography Global Physics sub-basin of the Salgado river, aims to present some constituent elements of the landscape in detail - the climatic aspects and geological-structural base. Therefore, we used survey work of these natural resources by official organ of the Brazilian State (Ministry of Mines and Energy - MME / Project RADAMBRASIL, Superintendence for the Northeast Development - SUDENE, Brazilian Institute of Geography and Statistics - IBGE, Ceará Meteorology Foundation and Water Resources - FUNCEME, Company Water Management - COGERH), as well as theses and academic publications on the study area.

Keywords: Geosystem. Cariri Cearense. Landscape. 


\section{Introdução}

O semiárido nordestino caracteriza-se fisiograficamente pelas vastas extensões pediplanadas, em sua maioria esculpidas em rochas cristalinas Pré-Cambrianas com solos rasos e pedregosos. Os cursos d'água são em predominância de regime intermitente, e a vegetação de caatinga é a mais encontrada. Estes elementos estão direta ou indiretamente relacionados ao seu clima, quente com chuvas irregulares e concentradas.

Do ponto de vista ocupacional, as áreas sertanejas semiáridas encontram-se fracamente povoadas, com cidades pequenas e propriedades rurais predominantemente de grande e médio porte, onde se pratica uma agricultura tradicional e uma pecuária extensiva voltada para o abate.

As bacias hidrográficas do Estado do Ceará apresentam certas características comuns: em geral são temporários, intimamente ligados à pluviosidade; junto aos relevos das serras e dos seus sopés são mais favorecidas pelas precipitações mais elevadas e melhor distribuídas, tendo os cursos d'água sua drenagem assegurada durante quase todo o ano; ao contrário, junto aos relevos aplainados dos sertões os rios secam no fim da estação chuvosa.

A bacia do rio Jaguaribe é a mais extensa e importante do estado do Ceará ocupando uma área de aproximadamente $72.000 \mathrm{~km} 20$ aspecto desta bacia é o de uma vasta depressão, ocupada nas partes mais baixas $(100-250 \mathrm{~m})$ por glacis sertanejos e bordejada por relevos de altitudes superiores a 700 e 800 metros (JACOMINE et al, 1973, p. 14).

A sub-bacia hidrográfica do rio Salgado, afluente da Bacia do rio Jaguaribe, está situada na porção sudeste do Estado do Ceará, inscrita num macropolígono cujas coordenadas abrangem $6^{\circ} 00^{\prime}$ a $7^{\circ} 50^{\prime}$ de latitude Sul e $38^{\circ} 30^{\prime}$ a $39^{\circ} 45^{\prime}$ de longitude Oeste. Com uma área drenada de 13.450,94 km², correspondente a 9,07\% do território estadual (IPECE, 2011), é composta por 23 municípios (FIGURA 01), e conta com uma população de 899.670 pessoas (IBGE, 2010).

O rio Salgado, com extensão de $308 \mathrm{~km}$, tem suas nascentes na Chapada do Araripe, na divisa dos estados de Ceará e Pernambuco, e em seu curso reúne drenagens originadas nas terras altas nos limites do Ceará com Pernambuco, Paraíba e Rio Grande do Norte tendo como principais afluentes os rios Batateiras, Granjeiro, Riacho do Saco, Riacho Lobo, rio Carás, Riacho São José, rio Missão Velha, Riacho dos Porcos, Riacho do Cuncas, Riacho Olho D'água, Riacho Rosário e Riacho São Miguel. Seus terrenos são formados $85 \%$ de rochas cristalinas e $15 \%$ de rochas sedimentares, estando os melhores aquíferos localizados na Bacia Sedimentar do Araripe (COGERH, 2007).

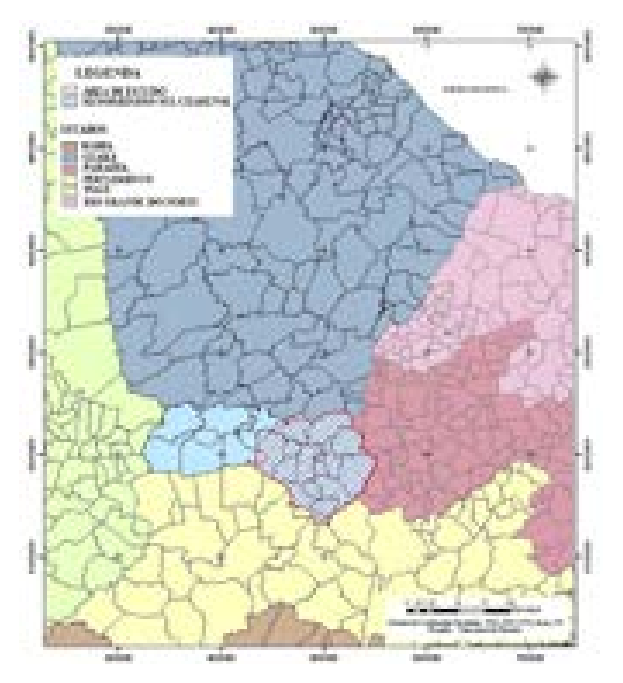

FIGURA 01 - Localização da área da subbacia do rio Salgado na Mesorregião Sul cearense. Fonte: RIBEIRO, 2012. 
Nas vertentes da chapada do Araripe, o rio possui declividades muito acentuadas, que vão se tornando mais suaves à medida que atravessa o Planalto Sertanejo e se aproxima da Depressão Sertaneja. As declividades do talvegue variam de 0,1\% a 8\%, sendo a média 0,18\% (GATTO, 1999)

Tem suas áreas em sua maioria utilizadas para a agropecuária onde se destaca a prática de sequeiro; as técnicas de preparação do solo nesta sub-bacia são rudimentares, destacando-se as coivaras e queimadas, deixando o solo empobrecido. Fazem parte desta paisagem também grandes espaços com plantações de cana-de-açúcar em áreas do vale do Cariri, próximo à Chapada do Araripe, ocupados por planícies aluviais A criação de gado na região, que teve início na época do Brasil colônia, é feita de forma extensiva e não levou em consideração a fragilidade da Caatinga, principal ecossistema da região, utilizando-se de métodos ambientalmente degradadores para sua expansão e reprodução.

A área escolhida para o estudo, municípios desta sub-bacia incluídos na Mesorregião Sul Cearense - Abaiara, Aurora, Barbalha, Barro, Brejo Santo, Caririaçu, Crato, Jardim, Jati, Juazeiro do Norte, Mauriti, Milagres, Missão Velha, Penaforte e Porteiras - ocupa 8.112,63 $\mathrm{km} 2$, equivalente a $61 \%$ da área da sub-bacia do rio Salgado, e 5,59 \% do território cearense, e conta com uma população de 710.648 habitantes (IBGE, 2010), onde um crescimento demográfico na casa dos $11 \%$ vem modificando a paisagem de forma nítida.

Para uma melhor caracterização geoambiental da área de estudo, optou-se apresentar os elementos constituintes da paisagem de acordo com a conceituação geossistêmica de Bertrand (1971), uma vez que este agrega estudos sobre fenômenos espaciais, geográficos, em que os elementos físico-biológicos e sócio-econômico-culturais se relacionam e produzem um espaço diferenciado. Adicionada à visão integrativa da paisagem, foram analisadas de forma mais específica, as relações entre os elementos paisagísticos com os processos e formas do relevo da área.

O conceito de geossistema de Bertrand (1971) expressa o sentido de uma geografia física global (espaço geográfico), composto de dois subconjuntos: um físico e outro humano, resultante da combinação dinâmica de elementos físicos, biológicos e antrópicos. Esta relação resulta da combinação entre o potencial ecológico (relevo, clima e hidrologia), a exploração biológica (vegetação, solo e fauna) e a ação antrópica.

Nesta primeira parte, serão examinadas algumas propriedades que compõem o potencial ecológico, das áreas drenadas pela sub-bacia do rio Salgado, onde trataremos das características e dinâmica climáticas assim como das litologias e estruturas geológicas. Em artigos posteriores serão tratadas as demais características da área.

\section{Dinâmica e características climáticas regionais}

De modo geral, o clima da Região Nordeste caracteriza-se pela ocorrência de dois períodos definidos, um mais longo, seco, intercalado por um pluvial curto e irregular, que pode não acontecer. Possui temperaturas elevadas - com a média para o mês mais frio sempre acima de 180 C, devido às suas baixas latitudes (FIBGE, 1977)

As chuvas no interior nordestino, e consequentemente na área em foco, são determinadas pelas oscilações na Zona de Convergência Intertropical (ZCIT). A Zona de Convergência Intertropical - área de encontro dos Alísios dos dois Hemisférios latitudinais - acompanha os 
deslocamentos do Equador térmico e tem sua posição meridional extrema aproximadamente no início do outono, época em que o anticiclone do Atlântico Sul atinge sua mínima pressão. Sendo zona de forte convecção, consegue transpor as barreiras orográficas e penetrar no interior (porém, já com sua umidade reduzida).

Além da ZCIT, outros sistemas atmosféricos atuam entre fevereiro e maio, quais sejam, Vórtices Ciclônicos de Ar Superior (VCAS), Frentes Frias, Linhas de Instabilidade, Sistemas Convectivos de meso-escala e Oscilação 30-60 dias. Desta forma, a estação chuvosa do Sertão nordestino, assim como em vários pontos de seu litoral norte, ocorre na sequência verão-outono e é determinada pelas ondulações da ZCIT a noroeste, aliada às penetrações das correntes perturbadas de oeste-noroeste (FUNCEME, 1990).

No Ceará, as chuvas mais significativas iniciam-se em dezembro e podem estender-se até junho ou julho, dependendo das condições oceânicas e atmosféricas atuantes. A região do Cariri, onde está localizada a sub-bacia do rio Salgado, é influenciada pelos sistemas e fenômenos climáticos descritos anteriormente no tocante aos índices de precipitação. Observando os números da quantidade de chuva dos anos de 1979 a 2008, e destacando os picos tanto dos anos mais secos e mais chuvosos, Silva et al (2010) percebeu que estes acompanham uma dinâmica que é fortemente influenciada por estes sistemas. Como dito anteriormente, a ZCIT (Zona de Convergência Intertropical) do Atlântico se mostra na faixa equatorial do Oceano Atlântico como uma zona de baixa pressão, onde há o encontro dos ventos alísios e intensa formação das cumulus nimbos, que são nuvens responsáveis por chuvas intensas. A zona de convergência ocorre em todo o globo, mas é na área do Atlântico que as nuvens estão mais concentradas, diferente do Pacífico, que, pela sua maior extensão, dispersa mais facilmente as nuvens.

Segundo Xavier et al (2003), a migração da ZCIT para o sul da Linha do Equador, interfere na promoção de uma maior precipitação no primeiro semestre do ano, sendo neste período que ocorrem as chuvas de maiores volumes. Dessa maneira a ZCIT do Atlântico interfere na promoção das chuvas na Região do Cariri, porém a antecipação do período concentrado de precipitação em relação ao norte do estado do Ceará (quadrimestre fevereiro a maio) faz com que se busque outro sistema na sua conjuntura climatológica, neste caso, frentes frias vindas do sul. Neste sentido, Molion e Bernardo (2000) lembram que um mecanismo importante de produção de chuva para o Nordeste meridional e oriental é a penetração de sistemas frontais, ou seus restos, entre as latitude $5^{\circ} \mathrm{S}$ e $18^{\circ} \mathrm{S}$.

Os postos pluviométricos de Barbalha, Crato, Juazeiro do Norte e Missão Velha, com período de observação de até 74 anos, acusam uma precipitação média anual, da ordem de 1.033 mm; para toda a Região do Cariri, a média é de 920 mm/ano (MMA, 1999). Para a sub-bacia do rio Salgado, Silva et al, (2010) analisando dados da FUNCEME de um período de 30 anos (1979-2008) encontraram como média anual de 889,4 mm, concentração das precipitações no trimestre fevereiro-março-abril, sendo o mês de março o mais chuvoso em 22 dos 23 municípios estudados (TABELA 01).

No Vale do Cariri, e em especial no alto da chapada do Araripe, há queda de temperatura e aumento da precipitação, indicando que ali o clima seria classificado em AW', ou seja, clima tropical chuvoso, com a estação chuvosa no outono. De acordo com os dados da SUDENE (JACOMINE et al, 1973), pode-se classificar o Cariri como pertencente a classe Amw', devido a seus índices de umidade. Esta classe caracteriza-se por tem o mês mais seco com precipitação abaixo de $60 \mathrm{~mm}$, ou seja, uma seca atenuada, sendo o clima um intermediário entre o Aw'(tropical chuvoso) e o Af (tropical úmido). 
A classificação climática de Köppen-Geiger, mais conhecida por classificação de Köppen foi proposta em 1900 pelo climatologista alemão Wladimir Köppen e aperfeiçoada várias vezes com a colaboração de Rudolf Geiger até a publicação da última versão em 1936. A classificação é baseada no pressuposto de que a vegetação natural de cada grande região da Terra é essencialmente uma expressão do clima nela prevalecente. Na determinação dos tipos climáticos de Köppen-Geiger são considerados a sazonalidade e os valores médios anuais e mensais da temperatura do ar e da precipitação.

\begin{tabular}{|c|c|c|c|c|c|c|c|}
\hline sanocino & $\begin{array}{l}\text { macsing } \\
\text { viscintoro }\end{array}$ & 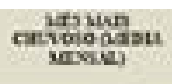 & $\begin{array}{l}\text { TRagring } \\
\text { sussitco }\end{array}$ & 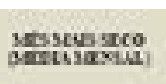 & 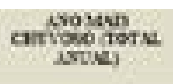 & A30Mussinco & 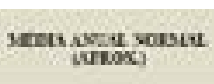 \\
\hline Anaraxa & Eaneser & Mrpor: & Exaces & $A g \times 0=01 \%$ & $1925=1711 \mathrm{man}$ & 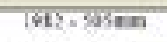 & $\infty \mathrm{sen}$ \\
\hline ATEOKA & tenaresx & 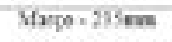 & 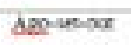 & $A g=00=0.06$ & $1445=1051 \mathrm{mon}$ & T661-31620 & $\sec , \cos$ \\
\hline BAKEATEA & $\tan \operatorname{tat} \operatorname{tax}$ & Mfxp̧o-24tmm & Ex-ats-iet & Aposeo. bism & ists-21 2 ism & $1962-55 \mathrm{~mm}$ & this=m \\
\hline SAREO & En-ait-kx & Mropo-100m & dar-imbax & Apposto-6ran & $10 \mathrm{~s}-1310 \mathrm{an}$ & $3007-4900=1$ & ostrim \\
\hline SKEIOSASTO & tenaitidx & Mecp-21:m & Bx-aside & Agavo-6:m & $1655-216 / \mathrm{an}$ & $5005-3060 \pi$ & socrian \\
\hline CARIRLACE & Enenox & Mape = 286em & Qherent & Agower. Cleses & $145=2111=$ & Xes-41:en & Hnow \\
\hline СЕАто & longentex & $\mathrm{Stepg}=257 \mathrm{~mm}$ & X-xesest & A $60000.0 \mathrm{sm}$ & $1585=1970 \mathrm{~mm}$ & $1905=345 n$ & to4tan \\
\hline GEAะULTEO & Isvaus:s & Sewo $=23 \mathrm{~km}$ & Whatext & 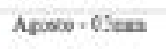 & $1585-2075 \mathrm{ma}$ & $1554=61$ las & t237ax \\
\hline JARDIM & Javedh & $\begin{array}{l}\text { Feverse - } \\
\text { 14tan }\end{array}$ & AE20อ1 $22 x$ & Aposove Ctans & 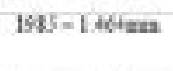 & $1982-313 a$ & $\operatorname{Mrn}$ \\
\hline min & fosectax & $31 \times 50-11) \mathrm{mm}$ & Ase-int-ax & 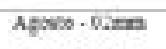 & $1545-101 \mathrm{tm}$ & [905s-306an & cosena \\
\hline JUAXIRO DO WOKTE & tonstax & 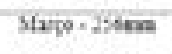 & Aascieas & Agxom-kese & $1545=1$ biten & $\mid \omega 05.50\}=$ & 2rear \\
\hline MLAtxm & $\tan \cos a x$ & stropo-500m & $B x \cdot x=0$ ent & Agseco-0tem & $1685-1.60 \mathrm{mn}$ & |कot:-3tsen & $87 \mathrm{~mm}$ \\
\hline MII:ACESS & Faniox & Wappo:216em & Dixacen & AExo.01m & $1445=101 \tan$ & test.desen & olien \\
\hline 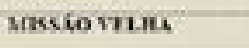 & Pesinox & Mrppo:24m & Lilag2-001 & Agsco:0:en & $1355=135 \mathrm{~cm}$ & $|90|=304 \pi n$ & क्का $\tan$ \\
\hline PEXAIORTK & Friaciks & Mego = $107 \mathrm{~m}$ & Aavionox & Agowe-0,an & $1985=1260 \mathrm{man}$ & 1482.3645 & cotno \\
\hline rokmukas & teraic-kx & Mtapo-17sm & b-kesed & A $8000.65 \mathrm{~mm}$ & 165 - 1 selow & topt-3t?min & Dotria \\
\hline
\end{tabular}

TABELA 01: DADOS DE PRECIPITAÇÃO DA SUB-BACIA DO RIO SALGADO NA MESORREGIÃO SUL CEARENSE - $1979-2008$

A classificação de Gaussen (JACOMINE et al, 1973), utilizada para determinação das regiões bioclimáticas, relaciona ritmo das temperaturas e precipitações durante o ano utilizando médias mensais e considerando os estados favoráveis e desfavoráveis para a vegetação. Fundamenta-se na determinação do período seco e índice xeotérmico. Nesta classificação, temos na área de estudo os tipos:

a) 4aTh - Tropical quente de seca acentuada, com seca de inverno eíndice xerotérmico entre 150 e 200, com 7 a 8 meses secos no ano, nas áreas da Depressão Sertaneja da subbacia do rio Salgado. Ë resultado do predomínio da Massa Equatorial Atlântica (mEa) que é estável. A curta estação chuvosa é consequência das penetrações da Massa Equatorial Continental (mEc) e das descidas da FIT (Frente Intertropical). A vegetação da área desta modalidade climática é a caatinga hiperxerófila apresentando todas as variações possíveis quanto ao porte e a densidade;

b) 4BTh - Tropical quente de seca média, com seca de inverno, índice xerotérmico entre 100 e 150, com 5 a 6 meses secos no ano, nas encostas da chapada do Araripe e no Cariri. A vegetação desta área é característica das regiões mais úmidas, predominando formações arbóreas. A formação florestal tem as características de uma floresta subcaducifólia;

Localizada ao leste da Bacia Sedimentar do Araripe, a sub-bacia do Salgado possui fatores naturais que complementam a dinâmica climática e principalmente a precipitação. Um destes fatores é a orografia que ocorre devido ao barramento ou mudança de direção da umidade e ventos originando chuvas de relevo e/ou chuvas convectivas, uma vez que os 
ventos úmidos guiados pelo processo de inércia, sobem ao relevo e precipitam na faixa de barlavento.

O relevo da Chapada do Araripe, com altitude de 900 metros, provoca uma divisão na distribuição das precipitações no encontro dos estados do Ceará, Paraíba, Pernambuco e Piauí. A umidade, geralmente vinda do litoral norte, faz da Chapada uma área de barlavento, aumentando as chuvas nas suas proximidades. Com menor impacto, mas também influenciando as precipitações de origem orográfica, tem-se a serra de São Pedro, a qual funciona como barlavento para os municípios de Granjeiro e Caririaçu, os quais também apresentam índices pluviométricos bastante elevados para a região (TABELA 01).

\section{Arcabouço Geológico-Geomorfológico Regional}

O território cearense tem sua compartimentação topográfica, decorrente basicamente de eventos que se verificaram no Período Pleistocênico, sem dúvida o de maior significado para análise dos fatos geomorfológicos. Esta compartimentação, com relevos desenvolvidos em terrenos do embasamento cristalino, ou em áreas de capeamentos sedimentares, decorre de um jogo de influências em que participam a estrutura geológica ao lado dos fatores paleoclimáticos e eustáticos, além da dinâmica morfogenética atual (SOUZA et al, 1979).

De acordo com Souza (1979), o relevo cearense engloba compartimentos bastante diferenciados, que se justificam por mecanismos genéticos complexos. Porém, há prevalência das superfícies rebaixadas do sertão recobertas por caatingas, que compreendendo extensas depressões periféricas de bordos de bacias sedimentares em contato com rochas do escudo cristalino, se estendem no sentido dos fundos dos vales ou se dirigem para o litoral através de declives suavemente inclinados. Estas depressões que atestam os efeitos pronunciados dos processos erosivos a que estiveram submetidas no Pleistoceno, são constantemente interrompidas pelo surgimento de formas residuais elevadas que constituem os relevos serranos.

Assim, como salienta Meireles (2007, p. 147) o atual estado do relevo cearense é sintetizado pela dinâmica topográfica, a complexidade das estruturas geofísicas e a diversidade de lineamentos, a partir da ação conjunta dos processos denudacionais perante

\section{Evolução Geológica Regional e suas Litologias}

A área da sub-bacia do rio Salgado está inserida na Província Borborema, entidade tectônica Neoproterozóica (Brasiliana - Pan-Africana), parcialmente encoberta por sedimentos Fanerozóicos de bacias interiores e marginais do Nordeste brasileiro - na área em estudo, da Bacia Sedimentar do Araripe.

A Bacia Sedimentar do Araripe está implantada sobre terrenos pré-cambrianos da Zona Transversal da Província Borborema, no domínio do Sistema de Dobramento PiancóAlto Brígida, no seu limite com a zona geotectônica de Teixeira (BRITO-NEVES, 1990 in PONTE e PONTE FILHO, 1996), e tem seu arcabouço estrutural constituído por sequências estratigráficas, limitadas por discordâncias regionais. Segundo Assine (2007, p.371) estas discordâncias "representam o registro fragmentário de embaciamentos gerados em ambientes tectônicos distintos". 
A Província Borborema, também chamada de Região de Dobramentos do Nordeste, de idade neoproterozóica, apresenta estruturação bastante complexa, onde predominam dobramentos intensos e intrusões batolíticas ígneas (na maioria granitóides), sendo dividida por grandes lineamentos. $\mathrm{Na}$ área basal da bacia do Araripe, são distintos dois tipo de domínios: terrenos metassedimentares e metavulcanossedimentares (sistemas de dobramentos) e terrenos gnáissicos-migmatíticos (maciços) (PONTE e PONTE FILHO, 1996).

De acordo com Santos e Brito Neves (1984) as faixas metassedimentares alternam com os terrenos gnáissicos-migmatíticos geralmente delimitados pelos lineamentos, feições marcantes e características da região, expressos por zonas cataclásticas e miloníticas.

Dentre os sistemas de lineamentos, destaca-se a Zona Transversal, extensa área com estruturas com direcionamento geral leste-oeste, estendida desde a região dos litorais dos estados da Paraíba e Pernambuco até a parte oriental do estado do Piauí, onde é recoberta pelas camadas sedimentares da Sinéclise do Parnaíba. Esta zona limita-se ao sul com o Lineamento de Pernambuco ou de Floresta e ao norte com o Lineamento de Patos ou da Paraíba, do qual fazem parte extensas zonas de cisalhamento (PONTE e PONTE FILHO, 1996).

Os setores da sub-bacia do Salgado em foco desenvolvidos em terrenos cristalinos ocorrem na Zona Transversal, aflorando ao redor da Bacia Sedimentar do Araripe, formando, muitas vezes, seus limites sob forma de serras e cristas, e sendo constituídos primordialmente de rochas do Grupo Cachoeirinha.

Segundo o Projeto RADAMBRASIL (GOMES et al, 1981) o Grupo Cachoeirinha compreende um pacote vulcanossedimentar metamórfico que ocorre desde a região de Ouricuri (PE) estendendo-se para norte até Lavras da Mangabeira (CE), sendo inserido na faixa de dobramentos Piancó-Alto Brígida, com uma estruturação tectônica formada por um amplo redobramento deitado. Litologicamente constitui-se de uma associação de micaxistos, filitos, metassiltitos, metavulcãnicas, quartzitos, lentes de calcários metamórficos, metaconglomerados, itabiritos, metarítimitos e metacherts, cortados por corpos ígneos de natureza granítica, granodioríticas e diorítica em forma de stocks e batólitos (GOMES et al, 1981).

A unidade mais representativa na área, a Formação Santana dos Garrotes, basal do Grupo Cachoeirinha, é constituída por metapelitos, metasiltitos, metarenitos finos (metarritimitos), predominantes, com raras metasubvulcânicas félsicas e metavulcânicas intermediárias na porção inferior, e várias soleiras/derrames de metavulcânicas félsicas posicionadas principalmente no topo, datadas em cerca de 660-620 Ma. Além destes litotipos são observadas, numa posição estratigraficamente intermediária, camadas de formações ferríferas e mármores (MEDEIROS e SÁ, 2009). Segundo Brito Neves et al (2005), esta formação é caracterizada por pacotes turbidíticos areno-argilosos (com alguns metagrauvacas e metassedimentos químicos ferríferos) de baixo grau de metamorfismo, com esparsas intercalações de rochas metavulcânicas básicas, intermediárias e ácidas, provavelmente de ambiente marinho. Estas rochas são observadas nos setores N-NE e SE da área de estudo, formando amplos pediplanos do Planalto Sertanejo (FIGURA 02).

Assim como as demais bacias interiores do Nordeste brasileiro, a bacia do Araripe tem sua evolução relacionada aos eventos associados ao rifteamento de Gondwana no Eocretáceo e à abertura do Atlântico sul iniciada no Jurássico superior, os quais reativaram falhas antigas do embasamento précambriano (Reativação Wealdeniana), provocando basculamentos que resultaram em altos (Horsts) e baixos (Grabens) estruturais. Segundo Brito-Neves (1990 apud PONTE e PONTE FILHO, 1996, p. 29) 
“a trama estrutural do embasamento precambriano impôs um marcante controle na arquitetura da zona de riftes do Araripe, cuja geometria se desenvolveu obedecendo e aproveitando descontinuidades estruturais preexistentes".

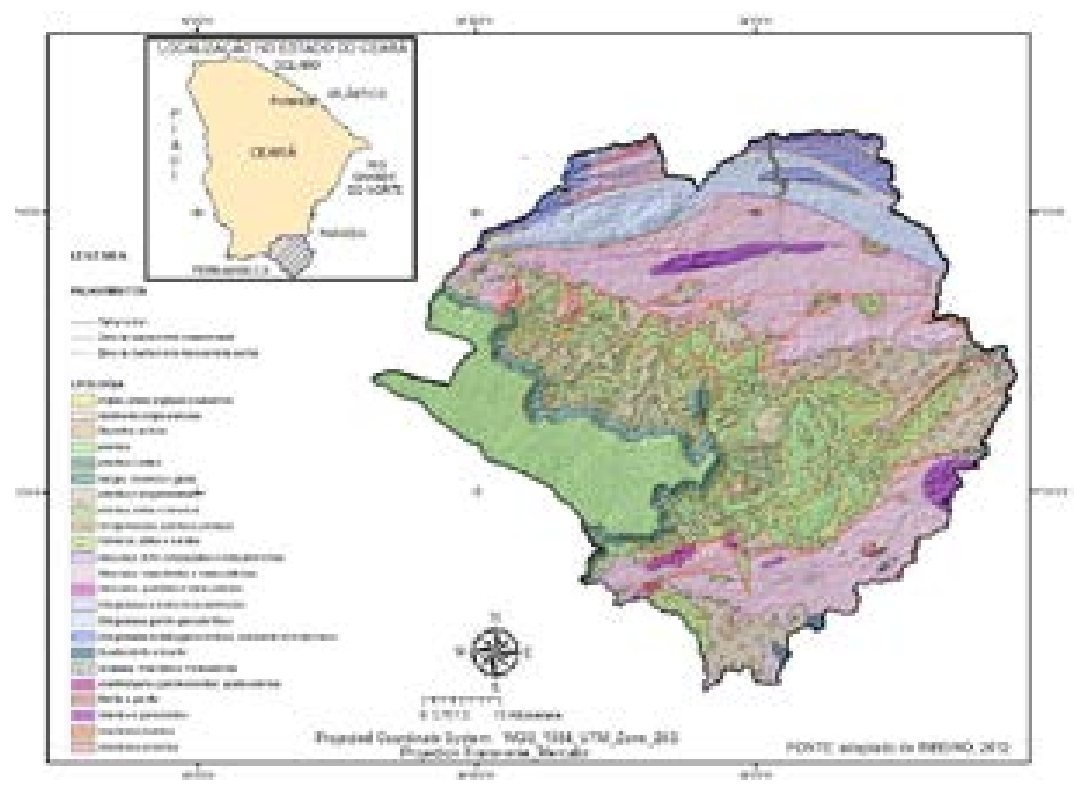

FIGURA 02 - MAPA GEOLÓGICO DA SUB-BACIA DO RIO SALGADO NA MESORREGIÃO SUL CEARENSEte: RIBEIRO, 2012.

De acordo com Matos (1999 apud CARDOSO, 2010), com o advento da principal fase de estiramento crustal de direção W-NW no Neocomiano, os lineamentos NE da área foram reativados como falhas normais, enquanto as zonas de cisalhamento transcorrentes do Neoproterozóico foram utilizadas para o balanceamento mecânico entre os blocos adjacentes. Assim, "o formato sigmoidal da megazona de cisalhamento de Patos propiciou esforços transtracionais gerando sub-bacias associadas a pontos de inflexão das falhas précambrianas" e na escala da bacia do Araripe "implantaram-se novas falhas de transferência, geralmente de direção NW, responsáveis pelo balanceamento local de tensões na crosta" (MATOS, 1999 apud CARDOSO, 2010, p. 10), resultando em grabens assimétricos colaterais (suas unidades fundamentais), com orientações SE-NW e mergulhos para NW (PONTE, 1996).

A literatura identifica na zona de ritfeamento, a estruturação de duas sub-bacias separadas por um alto estrutural interposto, denominado Horst de Dom Leme. A sub-bacia hidrográfica do Salgado, foco do estudo, está inserida na sub-bacia sedimentar do Cariri, formada por

"um conjunto de quatro grabens colaterais assimétricos (...) separados por três horsts que formam cristas intrabaciais, limitadas por falhas normais planares. Os grabens unitários recebem as designações de Crato-Juazeiro, Missão Nova, Jenipapeiro e Serrote das CacimbasPalestina. Os horsts interpostos são nomeados como Barbalha, Abaiara e Brejo-Santo-Mauriti "(PONTE e PONTE FILHO, 1996, p. 35). 


\section{Evolução Geológica Regional e suas Litologias}

Aevoluçãodosriftesintracontinentais, neocomianosnoNordestebrasileiro compreende três diferentes fases de subsidência: uma fase inicial, chamada de Pré-Rifte, caracterizada por lenta subsidência regional, uma fase de rápida subsidência local, chamada de Sin-Rifte e um retorno às condições de suave subsidência regional, assinalando a fase Pós-Rifte (PONTE et al, 1990, apud PONTE e PONTE FILHO 1996). A estas fases de subsidência, correspondem depósitos litoestratigráficos distintos, de acordo com as condições tectonoestruturais e ambientais vigentes em cada época.

Como salienta Ponte e Appi (1990) a Bacia Sedimentar do Araripe, corresponde a uma bacia de evolução policíclica, em cujo arcabouço estratigráfico podem ser distinguidas 'quatro sequências tectono-sedimentares limitadas por discordâncias regionais ou por hiatos paleontologicamente definidos: a Sequência Gama de idade siluro-devoniana (?); a Sequência Pré-Rifte, de idade neo-jurássica (?); a Sequência Rifte, de idade neocomiana e a Sequência Pós-Rifte de idade aptiana-albiana

As bases da litoestratigrafia da bacia sedimentar do Araripe foram estabelecidas por Beurlen (1962; 1963 apud ASSINE, 2007), o qual identificou as formações Cariri, Missão Velha, Santana e Exu e estimou para todo o pacote sedimentar um total de cerca de $850 \mathrm{~m}$. Porém, em sua moderna concepção, a estratigrafia da bacia do Araripe foi delineada na década de 1980, quando da intensificação de pesquisas na área para avaliação de seu potencial em hidrocarbonetos. A partir de estudos mais pormenorizados de gravimetria, foi demonstrada uma espessura bem superior que antigamente estabelecida por Beurlen, e mapeamentos geológicos propiciaram grande avanço no conhecimento da estratigrafia da bacia. Como aponta Arai (2006, apud ASSINE, 2007) "o arcabouço basilar para a Bacia do Araripe foi estabelecido pelos trabalhos bastante sólidos de Ponte e Appi (1990) e Assine (1992)".

A descrição da lito-estratigrafia abaixo foi baseada nos trabalhos de Ponte e Appi (1990), Ponte (1992), e Assine (2007), representada pelo Quadro 01. De forma geral, estes trabalhos apresentam mesma litoestratigrafia para a bacia do Araripe, modificando por vezes, a denominação das camadas.

Assim, podemos resumir a litoestratigrafia da Bacia Sedimentar do Araripe na área de estudo como uma sobreposição de camadas predominantemente areníticas, ora associadas a rochas mas finas de origem fluvial e lacustre, ora a sedimentos originados em ambientes lacustres e marinhos rasos. Afloram na porção central da área estudada, prolongando-se no sentido oeste-leste, sob forma da Chapada do Araripe e suas encostas e de colinas e colinas suavizadas no pediplano. 


\begin{tabular}{|c|c|c|c|c|c|c|c|}
\hline$\frac{5}{2}$ & $\frac{8}{3} \frac{3}{2}$ & nectontes & 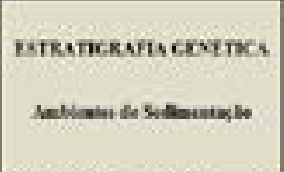 & Lrotocts & $\frac{8}{6}$ & 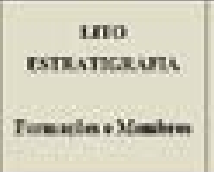 & $\begin{array}{l}\text { tocusustors } \\
\text { nusuces }\end{array}$ \\
\hline 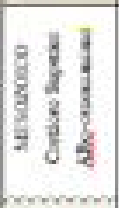 & \multirow{4}{*}{$\frac{1}{8}$} & 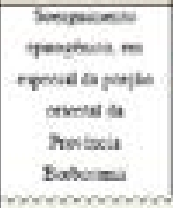 & 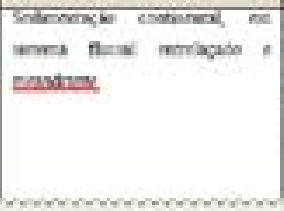 & 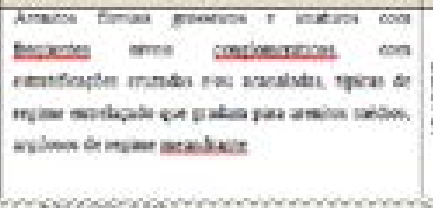 & 为 & 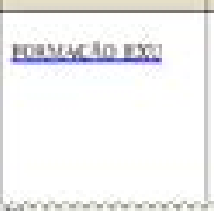 & 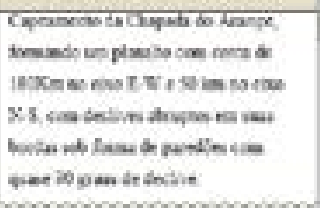 \\
\hline & & & & bicowerar & \multicolumn{3}{|r|}{ 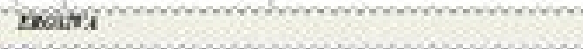 } \\
\hline \multirow[b]{2}{*}{ 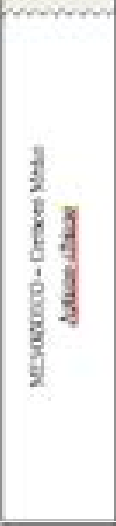 } & & 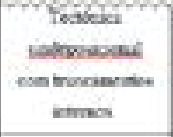 & 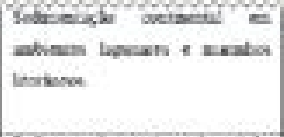 & 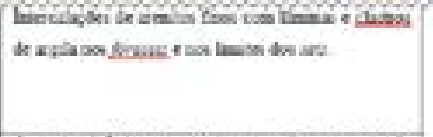 & & $\begin{array}{l}\text { Fonsucsio } \\
\text { Alevensa }\end{array}$ & 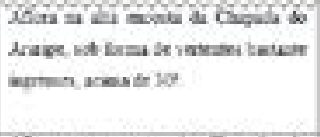 \\
\hline & & Nantik & 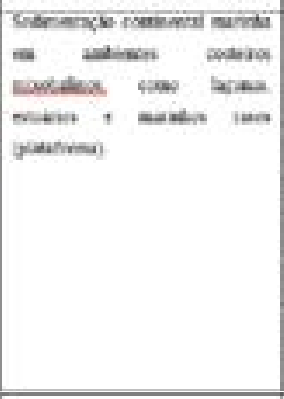 & 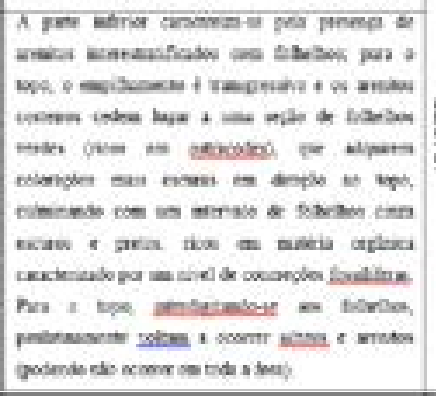 & $\frac{5}{3}$ & 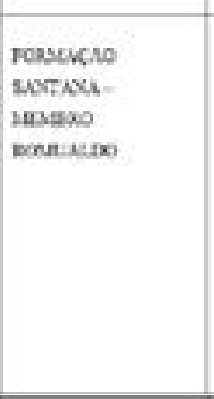 & 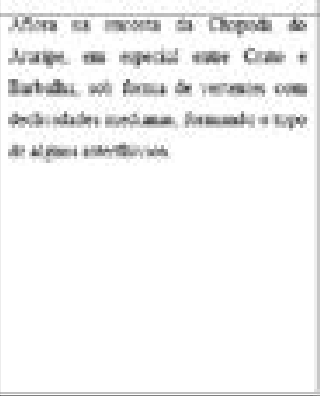 \\
\hline \multirow{4}{*}{\multicolumn{8}{|c|}{ 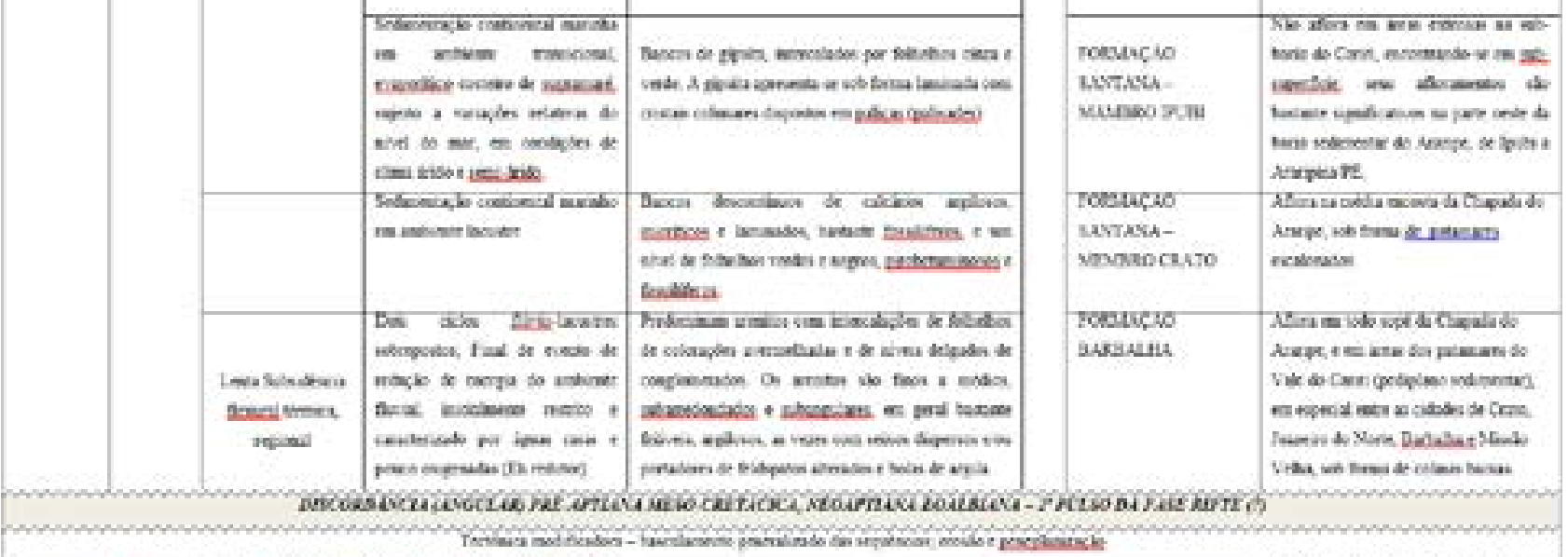 }} \\
\hline & & & & & & & \\
\hline & & & & & & & \\
\hline & & & & & & & \\
\hline s & 蒠 & 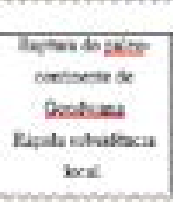 & 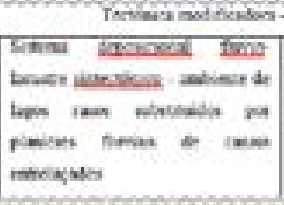 & 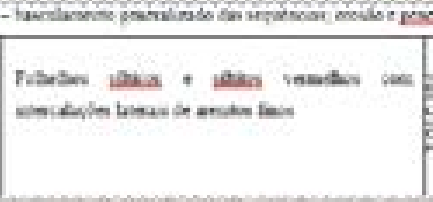 & है & $\begin{array}{l}\text { Posencio } \\
\text { Atheses }\end{array}$ & 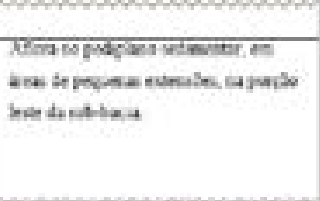 \\
\hline & & & & ensovaivat & & & \\
\hline \multirow[t]{3}{*}{ 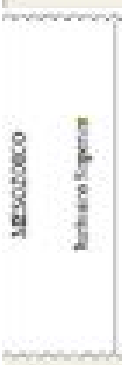 } & \multirow[t]{3}{*}{ 营 } & \multirow{3}{*}{ 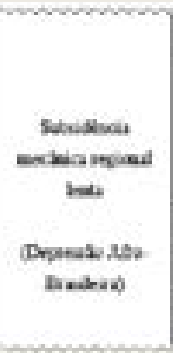 } & 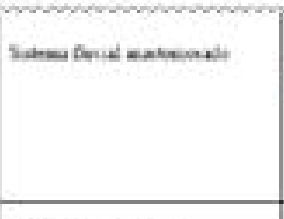 & 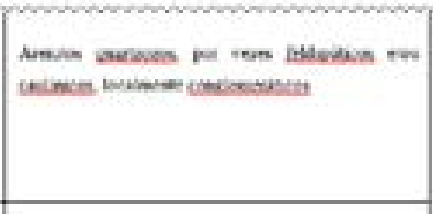 & \multirow{3}{*}{$-\frac{3}{3}$} & 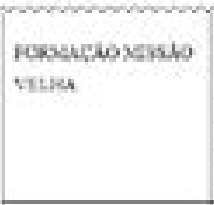 & 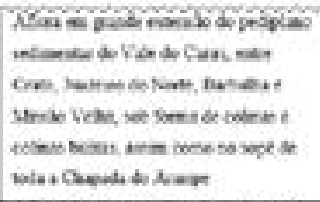 \\
\hline & & & swem bneras & 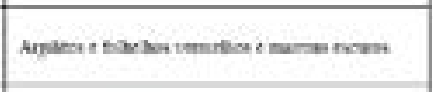 & & \multirow{2}{*}{ 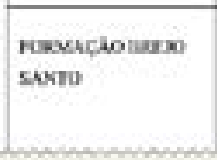 } & \multirow[t]{2}{*}{ 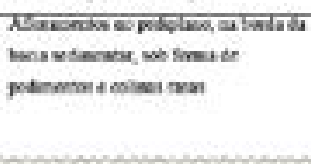 } \\
\hline & & & 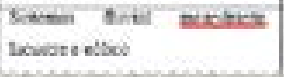 & 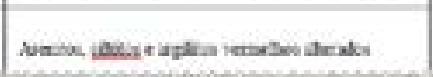 & & & \\
\hline \multicolumn{8}{|c|}{ Asconitiva } \\
\hline है & हैं & $\begin{array}{l}\text { Ralinas } \\
\text { sthes }\end{array}$ & 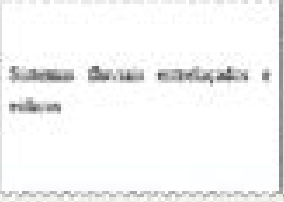 & 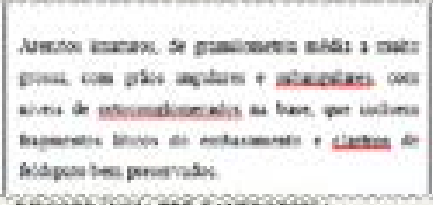 & & 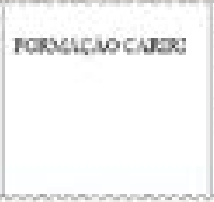 & 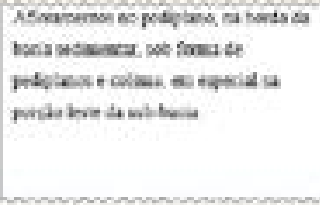 \\
\hline
\end{tabular}




\section{Considerações Finais}

A realidade socioambiental das áreas semiáridas nordestinas apresenta, desde sua ocupação, uma desarticulação crônica entre o potencial e fragilidade ambientais, e as técnicas utilizadas para a produção. Baseadas em experiências exógenas, a maioria dos projetos de desenvolvimento realizados na região não produzem efeitos realmente duradouros e muitos, pelo contrário, causam danos, por vezes irreversíveis ao ambiente.

Como afirma Christofoletti (1999, p. 35)

"os sistemas ambientais representam entidades organizadas na superfície terrestre, de modo que a espacialidade se torna uma das suas características inerentes. A organização desses sistemas vincula-se com a estruturação e funcionamento de (e entre) seus elementos, assim como resulta da dinâmica evolutiva".

Assim, a paisagem torna-se conceito básico nos estudos sobre fenômenos espaciais, geográficos, em que os elementos físico-biológicos e sócio-econômico-culturais se relacionem e produzam um espaço diferenciado.

Desta forma, buscou-se, neste primeiro artigo sobre a Geografia Física Global da subbacia do rio Salgado, fazer uma caracterização pormenorizada dos aspectos climáticos e da base geológico-estrutural da área.

Foram utilizados para esta caracterização trabalhos de levantamentos destes recursos naturais por órgão oficiais do Estado brasileiro (Ministério de Minas e Energia - MME/ Projeto RADAMBRASIL, Superintendência para o Desenvolvimento do Nordeste - SUDENE, Instituto Brasileiro de Geografia e Estatística - IBGE, Fundação Cearense de Meteorologia e Recursos Hídricos - FUNCEME, Companhia de Gestão dos Recursos Hídricos - COGERH), assim como de teses e publicações acadêmicas sobre a área de estudo.

Nos próximos artigos, serão apresentadas as demais características geoambientais da área focada, como relevo, solos, cobertura vegetal e evolução do uso-ocupação, como forma de subsidiar novas pesquisas que busquem compreender a dinâmica geográfica do Cariri cearense.

\section{Referências}

ASSINE, M.L. Bacia do Araripe. Boletim de Geociências. Rio de Janeiro, v.15, n.2, p.371-389, maio/Nov.2007

BERTRAND, G. Paisagem e Geografia Física Global - esboço metodológico. Cadernos de Ciência da Terra. São Paulo: USP/IG, 1971. n. 13.

BRITO NEVES, B.B.; VAN SCHMUS, W.R.; KOZUCH, M. SANTOS, E.J. e PETRONILHO, L. A Zona Tectônica Teixeira Terra Nova - ZTTTN -Fundamentos da Geologia Regional e Isotópica. Revista do Instituto de Geociências - USP, Geol. USP Sér. Cient., São Paulo, v. 5, n. 1, p. 5780, junho 2005. Disponível em www.igc.usp.br/geologiausp. Acesso em jun.2011.

CARDOSO, F.M.C. $\mathbf{O}$ graben de Palestina: contribuição à estratigrafia e estrutura do estágio rifte na Bacia do Araripe, nordeste do Brasil. Natal/RN: UFRN/PPGG, 2010 (Dissertação de Mestrado) 
COGERH. Vamos conhecer o Salgado. Crato/CE, 2007.13p. (Cartilha técnica)

FIBGE - FUNDAÇÃO INSTITUTO BRASILEIRO DE GEOGRAFIA E ESTATÍSTICA. Geografia do Brasil. Rio de Janeiro: SERGRAF - IBGE, 1977. v. 2: Região Nordeste.

FUNCEME. Balanço hídrico do Ceará. Fortaleza: 1990.

GATTO, L.C.S. (sup.) Diagnóstico ambiental da bacia do rio Jaguaribe - diretrizes gerais para a ordenação territorial. Salvador: IBGE, 1999. 77 p.

GOMES, J. R. C. et al. Geologia. In: BRASIL. Ministério das Minas e Energia. Secretaria Geral. Projeto RADAMBRASIL. Folhas SB. 24/25 Jaguaribe/Natal: geologia, geomorfologia, pedologia, vegetação e uso potencial da terra. Rio de Janeiro, 1981. (Levantamento de Recursos Naturais, 23).

IBGE. Censo demográfico 2010. Disponível em: http://www.ibge.gov.br/home/estatistica/ populacao/censo2010/resultados_dou/CE2010.pdf Acesso em dezembro de 2011.

IPECE. Perfil básico municipal 2011. Disponível em: http://www.ipece.ce.gov.br/ publicacoes/perfil_basico/perfil-basico-municipal-2011 Acesso em dez. de 2011.

JACOMINE, P. K. T., ALMEIDA, J.C. e MEDEIROS, L.A.R. Levantamento exploratórioreconhecimento de solos do Estado do Ceará. Recife: SUDENE, 1973. v.1, 301p.

MEDEIROS, V.C. e SÁ, E.F.J. O Grupo Cachoeirinha (Zona Transversal, NE do Brasil) redefinição e proposta de formalização. Revista de Geologia, v. 22, n. 2, p. 124-136, 2009. Disponível em: http://www.revistadegeologia.ufc.br/documents/revista/2009/11_2009.pdf.

MEIRELES, A.J.de A. As unidades morfo-estruturais do Ceará. In : BORZACCHIELLO DA SILVA, J; CAVALCANTE, T. C.e DANTAS, E. W.C.(org.) Ceará: um novo olhar geográfico.2.ed. atual. Fortaleza: edições Demócrito Rocha, 2007. p.141-168

MMA/FUNDETEC/URCA. Projeto Araripe. Crato: 1999.

MOLION, L.C.B. e BERNARDO, S.O. Dinâmica das Chuvas no Nordeste Brasileiro. Congresso Brasileiro de Meteorologia, 11, Rio de Janeiro, 2000. Anais... Em http://www.cbmet.com/ cbm-files/12-7ea5f627d14a9f9a88cc694cf707236f.pdf. Acesso em 24/06/2010.

PONTE, F.C. e APPI, C.J. Proposta de revisão da coluna estratigráfica da Bacia do Araripe. In: Congresso Brasileiro de Geologia, 36, Natal. Anais... Natal/RN: SBG, 1990. v.1

PONTE, F.C. e PONTE FILHO, F.C. Estrutura geológica e evolução tectônica da Bacia do Araripe. Recife: DNPM, 1996.

PONTE, F.C; PONTE FILHO, F.C. Evolução tectônica e classificação da Bacia do Araripe. In: Simpósio sobre o Cretáceo do Brasil, 4. Águas de São Pedro (SP). Boletim...UNESP/IGCE, b1996. p.123-133. 
PONTE, F.C. Sistemas deposicionais na Bacia do Araripe, Nordeste do Brasil. In: Simpósio sobre Bacias Cretáceas Brasileiras, 2, Rio Claro, 1992. Resumos Expandidos... Rio, UNESP, p.81-84.

RIBEIRO, S.C. Etnogeomorfologia sertaneja: proposta metodológica para a classificação das paisagens da sub-bacia do rio Salgado/CE. Rio de Janeiro: UFRJ/PPGG, 2012. 284 p. (Tese de Doutorado)

SILVA, F. M. A.; LIMA, G. G.; REIS, G. P.; SOUZA, G. B. B.; LIMA, F. J.; RIBEIRO, S. C. Análise das precipitações pluviométricas na sub-bacia do rio salgado, sul cearense (1979 - 2008). In Simpósio Nacional de Climatologia Geográfica, 9, 2010, Fortaleza. Anais... Fortaleza: UFC, 2010. 1 CD.

SOUZA, M.J.N.; LIMA, F.A.M. e PAIVA, J.B. Compartimentação geomorfológica do estado do Ceará. Ciência Agronômica, 9 (1-2):77-86. Fortaleza/CE, dezembro/1979.

XAVIER, T.M.B.; XAVIER, A.F.S.; DIAS, M.A.F.S. e DIAS, P.L.S. Interrelações entre eventos ENOS (ENSO), a ZCIT (ITCZ) no Atlântico e a chuva nas bacias hidrográficas do Ceará.

Revista Brasileira de Recursos Hídricos, v. 8, n.2, abr./jun.. 2003, p. 111-126. 